\title{
Impactos socioculturais e gênero nos reassentamentos da Usina Luis Eduardo Magalhães - TO*
}

\author{
Social and cultural impacts on gender \\ in resettlement, Plant Luis Eduardo \\ Magalhães - TO
}

\author{
TEMIS GOMES PARENTE** \\ Departamento de História \\ Universidade Federal do Tocantins \\ Palmas (TO) \\ Brasil
}

CYNTHIA MARA MIRANDA*** Departamento de Comunicação Social Universidade Federal do Tocantins Palmas (TO) Brasil

RESUMO O presente artigo se propõe a analisar os impactos socioculturais decorrentes da formação do reservatório com a construção da Usina Luis Eduardo Magalhães e revisitar alguns discursos desenvolvimentistas construídos pela imprensa local durante o processo de construção da usi-

\footnotetext{
* Artigo recebido em: 14/03/2013. Aprovado em: 11/11/2013

** Contato: temis.parente@uol.com.br.

***Contato: cynthiamara@mail.uft.edu.br.
} 
na. Pretende ainda dar destaque às lembranças das mulheres que foram reassentadas enfatizando o sentimento delas em relação à perda de um espaço que já não existe mais e o reforço das relações de gênero por meio de discursos que se reportam a lugares e tempos que costumeiramente são definidos como próprios de mulheres. A pesquisa privilegiou a História Oral. Entendemos que a importância da história oral, além de expressar a historicidade da experiência pessoal e o papel do indivíduo na história da sociedade, permite ampliar os conhecimentos e as informações sobre um passado recente através da versão de pessoas que o viveram.

Palavras-chave gênero, impactos socioculturais, reassentamentos

ABSTRACT This article aims to analyze the socio-cultural impacts arising from the formation of the reservoir with the construction of the Plant Luis Eduardo Magalhães and revisit some developmentalist discourses constructed by the local press during the construction of the plant. It also aims to highlight the memories of the women who were resettled emphasizing the feeling of them against the loss of a space that no longer exists and the strengthening of gender relations through discourses that relate to places and times that customarily are defined, themselves as women. The research focused oral history, since, in addition to expressing the historicity of personal experience and the individual's role in social history, oral history allows to extend the knowledge and information about the recent past through the release of people who lived.

Keywords gender, socio-cultural impacts, resettlement

O presente artigo se propõe a analisar os impactos sociais e culturais causados pela formação de um reservatório de água durante a construção da Usina Luís Eduardo Magalhães, no Rio Tocantins no Norte do Brasil, dentro da Amazônia Legal.

Desde a sua criação pela Constituição Federal de 1988, o Estado do Tocantins vem passando por importantes transformações, tanto espaciais quanto sociais. Dentre elas destacam-se as decorrentes das construções hidrelétricas, não só pela extensão da obra, mas também pelo impacto causado na vida de um grande número de pessoas.

A implantação dessas construções se apoiou no discurso desenvolvimentista do Estado, que propunha superar o atraso secular de uma região, promover a industrialização e, consequentemente, o desenvolvimento. Convém lembrar que esse discurso remonta ao período colonial e aos 
primeiros movimentos divisionistas do Estado de Goiás, no século XIX. ${ }^{1}$ $\mathrm{O}$ atraso do antigo norte de Goiás, hoje Tocantins, é recorrente em quase todos os estudos que abordam a criação do Estado, uma vez que foram as várias interpretações de atraso e de abandono da região que justificaram a idéia de divisão do Estado de Goiás. Defendia-se o desenvolvimento do norte de Goiás como uma forma de minimizar as disparidades regionais brasileiras.

Foi com esse discurso de superação de atraso que se iniciou a construção da Usina Luís Eduardo Magalhães - popularmente conhecida como Usina de Lajeado. Sabe-se, entretanto, que as construções de usinas, como todo empreendimento de grande porte, geram impactos imediatos, a médio e a longo prazo, no meio ambiente e nas sociedades tradicionais, bem como ultrapassam os limites de suas abrangências. Com a construção desses empreendimentos a população local é diretamente impactada com a desarticulação das formas de uso comunal de recursos naturais e fontes d'água, comprometimento da agricultura de vazante após a mudança dos regimes hidrológicos dos rios, bem como alteração da pesca tradicional por mudanças da ictiofauna devido às alterações dos níveis de oxigênio dos corpos d'água. ${ }^{2}$

Os efeitos desses impactos são diluídos nas justificativas que se criam para as construções desses empreendimentos, e a principal delas é a de que as construções de grandes hidrelétricas prioritariamente levam o desenvolvimento às regiões antes atrasadas.

Com a construção da Usina Luís Eduardo Magalhães não foi diferente. E isso pode ser percebido nas matérias que os jornais locais veiculavam quando a usina estava em fase inicial de construção:

\title{
O LAGO QUE VAI MUDAR O CENÁRIO TOCANTINENSE
}

\begin{abstract}
Pesquisas, obras de infra-estrutura e projetos turísticos preparam a Região Central do Estado para o reservatório da Usina Hidrelétrica Luís Eduardo Magalhães, um lago que vai ter uma extensão de $630 \mathrm{~km}^{2}$ e promete incrementar o turismo e a economia do Tocantins como um todo. Localizado bem no meio do cerrado, o enchimento certamente lembrará o dilúvio bíblico e as peripécias de Noé e sua Arca. Mas hoje, em vez de um robusto barco de madeira, os animais serão salvos pela tecnologia produzida pelo homem do III Milênio, e o homem já pode prever as conseqüências que os milhões de metros cúbicos de água irão trazer ao meio ambiente. ${ }^{3}$
\end{abstract}

1 OLIVEIRA, Rosy. A "invenção" do Tocantins. In: GIRALDIN, Odair (org.). A (trans)formação histórica do Tocantins. Goiânia: Editora da UFG, 2004.

2 ACSELRAD, Henri; SILVA, Maria das Graças da. Rearticulação sociais da terra e do trabalho em áreas de grandes projetos hidrelétricos na Amazônia: o caso de Tucuruí. In: ZHOURI, Andréia (org.). As tensões do lugar: hidrelétricas, sujeitos e licenciamento ambiental.,. Belo Horizonte: Editora UFMG, 2011. p.61-92.

3 Jornal do Tocantins, Palmas, 18/02/2001. 
Para quem manuseia as edições de jornais daquele período, fica claro que quase todas as matérias relativas à construção da Usina só salientavam as vantagens do empreendimento, não levavam em consideração os impactos para a população ribeirinha. Isso demonstra que os jornais, como documentos históricos, reproduzem os valores e o pensamento de uma classe. ${ }^{4}$

Para a população ribeirinha, com a construção da Usina e com a formação do reservatório, o Rio Tocantins perdeu todo o seu referencial. Desde o período colonial, com as descobertas das minas de ouro no norte da capitania de Goiás, o rio servia como elo de ligação e abastecimento da região mineradora. ${ }^{5}$ Essa ligação perdurou até meados do século XX, com a inauguração da BR-153 (Rodovia Belém-Brasília).

Desde os primeiros movimentos divisionistas de Goiás, articulados pelas elites locais, no início do século XIX, tornaram-se frequentes os discursos que incentivavam a navegação no Rio Tocantins, como forma de conquistar o desenvolvimento comercial e a autonomia econômica, tanto para o norte de Goiás como para toda a região norte do Brasil. É o que se pode perceber no relatório de Teotônio Segurando, para quem a região só sairia da crise decorrente do declínio da mineração através do estímulo à navegação comercial pelos rios Tocantins e Araguaia. Somente assim seria possível levar e trazer produtos, o que incrementaria as transações comerciais com outras regiões. ${ }^{6}$

Nas décadas de 1950 e 1960, com a construção da Belém-Brasília (BR-153), o Rio Tocantins deixa de ser não só o referencial econômico, de comunicação e de circulação das notícias procedentes do norte de Goiás, mas também o elemento desenvolvimentista da região, uma vez que quase todo o eixo comercial passa a girar em torno das margens daquela rodovia. Ali surgem novas cidades e desenvolvem-se as já existentes.

A partir da década de 1980, o Rio Tocantins volta a representar um valor simbólico sem precedentes para as populações ribeirinhas: as "praias" que se formam em todo o seu leito atraem investimentos de toda natureza. A exploração turística gera fontes de renda para uma grande parte da população mais carente das cidades ribeirinhas. Atuando como barqueiros, barraqueiros, ambulantes e comerciantes, os moradores locais, nas temporadas, aumentam suas possibilidades de ganho.

Com a criação do Estado em 1988, o Rio Tocantins volta a ser o foco de discussão: atribuem-lhe o papel de responsável pelo desenvolvimento

\footnotetext{
SANTOS, Jocyléia Santana. O jornal: fonte de pesquisa histórica. Revista Fontes, Palmas, v.1, n.1, 2002

5 PARENTE. Temis Gomes. Fundamentos históricos do estado do Tocantins. Goiânia: Universidade Federal de Goiás, 2003.

6 PARENTE. Temis Gomes. Fundamentos históricos do estado do Tocantins.

7 As "praias" nada mais são do que bancos de áreas formados nos leitos dos rios, como é o caso de Porto Nacional, ou também nas margens, como é o caso de Palmas e Peixe, cidades que ficam às margens do rio. A "temporada" ocorria entre os meses de maio a setembro, que é o período de verão na região.
} 
da região - um desenvolvimento que poderia ser viabilizado através da construção de grandes hidrelétricas em seu leito.

Até então a população local mantinha com o rio um sentimento de pertencimento, que foi rompido com a construção da Usina e a formação do reservatório. Em face disso, geraram-se impactos irreversíveis, como se pode perceber na narrativa a seguir:

O rio Tocantins era tudo pra gente. É como se fosse um pai. Era bom demais, lá meus meninos pescavam, eu pescava, lavava roupa, a gente banhava. Nos finais de semana, sábado, domingo, a gente passava o dia todinho. Era banhando, era pescando, lavando roupa (...) Lá a gente não precisava comprar frutas. Fazia vazante (...) o verão todinho, a gente estava plantando na beira do rio. E quando era no inverno plantava também e tinha as frutas. Tinha tudo. A gente fazia a feira, vendia na feira de Porto Nacional e de Taquaralto. Não tinha preocupação com comida e aqui na cidade tem que comprar tudo. ${ }^{8}$

\section{A Usina Luís Eduardo Magalhães}

A construção da Usina Hidrelétrica Luiz Eduardo Magalhães foi iniciada em $1^{\circ}$ de julho de 1998 , em uma área de $3,5 \mathrm{~km}^{2}$ no município de Lajeado (TO), a $50 \mathrm{~km}$ de Palmas. O reservatório formado com a construção da usina tem uma extensão de $170 \mathrm{~km}$ e abrange uma área total de 630 km², atingindo os municípios de Miracema, Lajeado, Palmas, Porto Nacional, Brejinhos de Nazaré e Impueira.

Dentre os estudos prévios, o de viabilidade - realizado, em 1996, pela empresa de consultoria Themag ${ }^{9}$ - resumiu os dados do diagnóstico social e econômico promovido diretamente nas áreas, direta e indiretamente, afetadas pelo empreendimento. O documento produzido por essa empresa registrou os seguintes dados: a área a ser inundada seria da ordem de 75 mil hectares; no processo de construção, 1.526 famílias seriam afetadas, sendo 997 na área rural e 529 em áreas urbanas, totalizando 6.483 pessoas. Esse mesmo documento cita que $90 \%$ das pessoas que viviam na área rural - ouvidas durante o estudo de viabilidade - utilizavam o rio para pescar.

Segundo Silva Junior, ${ }^{10}$ a construção desses empreendimentos apresenta as seguintes ocorrências: com as notícias da implantação das usinas, propagam-se comentários, boatos, falas otimistas e pessimistas. Ou seja, é uma fase denominada por Silva Junior como a do início da desestrutu-

8 MESSIAS, Noeci Carvalho. Patrimônio cultural: entre o tradicional e a modernidade com a chegada da hidrelétrica de Lajeado, Porto Nacional - TO. Goiânia: Universidade Católica de Goiás, 2004 (Gestão do Patrimônio Cultural, Dissertação de mestrado).

9 THEMAG. Relatório de impacto sobre o meio ambiente. Usina Hidrelétrica Lajeado, nov. 1996, p.50.

10 SILVA JÚNIOR, José Maria. Reassentamentos rurais da Usina Hidrelétrica Luís Eduardo Magalhães - Tocantins: a efetividade do programa de remanejamento populacional quanto à sua sustentabilidade socioambiental. Palmas: Universidade Federal do Tocantins, 2005 (Ambiente, Dissertação de mestrado). 
ração social. E, em consequência, ocorre o aumento das tensões sociais, advindo daí a desestruturação econômica; com a pressão antecipada sobre os recursos naturais, seguem-se a especulação imobiliária urbana e rural, bem como a retração do mercado de trabalho.

Há, posteriormente, uma desestruturação social das comunidades urbanas e rurais, ocasião em que as pessoas são retiradas da área prestes a ser inundada. Evidenciam-se, então, as mais variadas consequências imediatas, tais como: mudança no padrão de comportamento da população rural e urbana, alteração do quadro demográfico e especulação imobiliária. Isso pode ser observado na reportagem a seguir:

Hidrelétrica inflacionou o mercado imobiliário nas proximidades da zona urbana - A procura de lotes aumentou cerca de $60 \%$ nos últimos dois meses, junto com a grande procura houve uma majoração nos preços, que nos últimos 30 dias chegou a subir $67 \%$. O setor imobiliário é o que mais tem crescido nos últimos 2 meses, repercutindo na majoração dos preços dos aluguéis e dos lotes urbanos em até 400\%. Até 8 mil pessoas devem vir morar na região em função da obra, para isto é prevista a construção de escola, posto de saúde e o funcionamento de comércio no canteiro de obra. ${ }^{11}$

Por outro lado, há a desestruturação econômica da população realocada, como a retração do mercado de trabalho e a possível marginalização social das pessoas que antes tinham atividades de subsistência. ${ }^{12}$ Isto sem contar com os impactos ambientais causados por essas construções de barragens.

\section{Impactos sociais ${ }^{13}$}

Doze anos após a inauguração da usina - ocorrida em 2001 - e a formação do lago, os impactos causados por essa hidrelétrica são visíveis. Com base em pesquisas já realizadas e em depoimentos de pessoas direta ou indiretamente impactadas, parece claro que esses grandes projetos desenvolvimentistas, principalmente as barragens nas bacias hidrográficas, que exigem o deslocamento compulsório de grande quantidade dos moradores locais, geram impactos em todos os sentidos. Isso é mais facilmente observado no tocante às pessoas mais carentes, pois inúmeras famílias de agricultores e de trabalhadores rurais são obrigadas a deixar suas terras, o

11 Jornal do Tocantins, Palmas, 12 a 13/11/1997

12 SILVA JÚNIOR, José Maria. Reassentamentos rurais da Usina Hidrelétrica Luís Eduardo Magalhães - Tocantins, p.65.

13 Segundo a abordagem centrada nos "impactos sociais", o processo de deslocamento compulsório é definido, sobretudo, pela sua natureza dramática, pelos seus acelerados e traumáticos processos de mudança sociocultural e, principalmente, por impor limites à capacidade de resposta dos deslocados perante as imposições da obra (partem do princípio de que a obra possui caracteres próprios de desenvolvimento) e das imposições das agências governamentais responsáveis. RODRIGUES, Cintya Maria Costa. Águas aos olhos de Santa Luzia: um estudo de memórias sobre o deslocamento compulsório de sitiantes em Nazaré Paulista (SP). Campinas: Editora da Unicamp/Centro de Memória da Unicamp, 1999, p.22. 
que lhes acarreta problemas de subsistência. Na maioria das vezes, essas famílias são realocadas ou em áreas que não dispõem de condições para o cultivo de alimentos ou mesmo na zona urbana. ${ }^{14}$

Observaram-se também impactos consideráveis na vida dos produtores rurais que plantavam em suas terras e foram realocados em outras. A avaliação inicial quanto à realocação era bastante positiva, uma vez que o problema estava sendo mascarado, pois a empresa empreendedora, além de fornecer cestas básicas, contribuía com insumos e maquinários agrícolas. Quando cessaram esses benefícios, o impacto foi muito grande para os reassentados, pois a terra não era própria para o plantio, e os pequenos produtores não tinham condições de bancar os insumos necessários. ${ }^{15}$

O processo de realocação das famílias ribeirinhas resultou no enfraquecimento da unidade familiar, pois, diante da necessidade de procurar trabalho assalariado na cidade, houve, nas novas vilas criadas, um esvaziamento de homens, uma vez que eles não tinham onde trabalhar. ${ }^{16}$

Já nas áreas urbanas, os impactos maiores se concentraram na geração de empregos, principalmente nas temporadas de praia do Rio Tocantins, pois nesses períodos surgiam possibilidades de ganhos para os barqueiros, que atravessavam os turistas para as praias. Com a formação do reservatório, as praias ficaram submersas, e eles perderam a oportunidade de ganhar o seu sustento. ${ }^{17}$ Os barraqueiros - que eram os proprietários de bares e restaurantes nas praias - também enfrentaram a mesma situação. É o que se pode perceber nas reportagens dos jornais locais da época. Ao reproduzirem as falas de algumas pessoas impactadas, é possível constatar as reivindicações e os sentimentos de revolta de várias categorias de profissionais. Durante o período de negociações para o pagamento das indenizações, os barraqueiros acamparam na porta da empresa, como registra o seguinte trecho de jornal:

Investco não pretende indenizar barraqueiros: o gerente de meio ambiente, Joaquim Cardoso Lemos, explicou ontem que não vai indenizar os barraqueiros e barqueiros que estão acampados na frente do escritório da empresa, no centro de Palmas, há mais de uma semana. ${ }^{18}$

14 Essas observações estão em quase todas as entrevistas gravadas e compiladas, realizadas pelas/os pesquisadoras/es do Núcleo de Estudos das Diferenças de Gênero - NEDIG - no Campus de Porto Nacional - TO. Desde 2004 com a aprovação do primeiro projeto, pelo CNPQ, teve início a formação de um acervo com todas as entrevistas devidamente catalogadas. Algumas partes dessas fontes já constam em observações de trabalhos já publicados pelas pesquisadoras/es, porém, são sempre revisitadas e interpretadas em trabalhos que abordam enfoques pertinentes.

15 Informações fornecidas pelos assessores do Movimento dos Atingidos por Barragens (MAB), de Porto Nacional (TO).

16 PARENTE, Temis Gomes. Lembranças de outrora: história e memória de mulheres desterritorializadas. In: DEL RíO, José M. Valcuende; CARDÍA, Laís M. (org.). Territorialização, meio ambiente e desenvolvimento no Brasil e na Espanha. Rio Branco: EDUFAC, 2006, p.69.

17 MESSIAS, Noeci Carvalho. Patrimônio cultural, p.70.

18 Jornal do Tocantins, Palmas, 14/07/2001. 
Nessa mesma reportagem, os barraqueiros alegam que haviam trabalhado durante dez anos na praia e que a Investco não estaria levando esse dado em conta. As associações de barqueiros e barraqueiros foram formadas a partir da década de 1980, quando os governos municipais e estadual começaram a investir nas áreas de lazer, através do turismo das praias, no período de verão. Os objetivos dessas associações eram, por um lado, o de melhor organizar e explorar o turismo local, e, por outro, o de evitar a concorrência por parte dos não-associados, o que era muito comum nas temporadas de praia.

Desse modo, quando se formou o reservatório, essas associações já existiam, e o que elas reclamavam era justamente a indenização por terem perdido a possibilidade de ganho, garantida com as travessias do rio e com os restaurantes e bares que montavam durante as temporadas de verão. Manzano e Manzano retratam assim a complexidade e a extensão dessas atividades:

Porto Nacional sempre foi um pólo de turismo regional, nos meses de seca, principalmente em julho, em virtude das águas claras, lindas praias, que formavam no Rio Tocantins e do clima constantemente quente, mas agradável nessa época. (...) A praia principal ficava numa ilha, sendo necessário usar um barco para chegar nela. Os que não podiam pagar iam numa balsa da Prefeitura. Nos primeiros anos ia pouca gente para a ilha, mas à medida que foram aumentando os turistas, foi melhorando (ou piorando) a infra-estrutura das praias. Logo que as chuvas paravam, já se iniciavam os preparativos dos barraqueiros para construírem seus bares e restaurantes na ilha, tudo feito de madeira e palha. As famílias mais abastadas também construíam suas casas para passar as férias na ilha. A Prefeitura montava um grande palco, com aparelhagem de som potente e contratava bandas conhecidas, no país, para tocar nos finais de semana. Nos últimos tempos, na ilha havia supermercado, banco, boate, posto de saúde, água encanada, luz elétrica, quadra de vôlei e de futebol. As famílias que não gostavam dessa badalação faziam suas casas de férias em uma ilha mais afastada e abaixo da cidade. ${ }^{19}$

Para justificar o desaparecimento dessas atividades, o poder público e a empreendedora da obra, a Investco, formularam vários discursos e, nesse contexto, os jornais e a imprensa assumiram o papel de reforçá-los e legitimá-los, como se pode observar na seguinte reportagem:

Energia é fonte de investimentos: o início das operações da Usina Hidrelétrica Luís Eduardo Magalhães, em Lajeado, e a construção da mais três usinas hidrelétricas no estado vão garantir a atração de investidores para o Tocantins em 2002, além de oferecer a energia necessária para a promoção do desenvolvimento dos setores, do comércio e serviços e, principalmente, da indústria. A expectativa do 
governo e do meio empresarial é de atrair grandes potências da economia para

o Estado, colaborando também para a geração de emprego e renda. ${ }^{20}$

Com base no trecho, vê-se que o jornal enaltece o empreendimento através da apresentação dos números relativos aos investimentos.

No que se refere ao desaparecimento das praias que ocorriam somente em um determinado período do ano, a justificativa era a de que, a partir daquele momento, elas seriam definitivas e, consequentemente, as estruturas nelas existentes funcionariam o ano inteiro. Isso criou expectativas nos barqueiros, barraqueiros e comerciantes, que dependiam dessa atividade para sobreviver. Depois de um determinado tempo, ficou claro que não havia motivos para expectativas: a nova praia de Porto Nacional, "construída" para ser definitiva, não era o que a população esperava, seja para o lazer, seja para as atividades dos barqueiros, barraqueiros e comerciantes. Por não corresponder aos anseios da população, hoje, a praia encontra-se abandonada, até mesmo nos meses de verão.

Já em Palmas, o empreendedor divulgava, em anúncios publicitários, a construção de uma avenida, a Beira Rio, de mais de vinte quilômetros, em que haveria vários hotéis, clubes náuticos, playgrounds, áreas de lazer e recreação, num arranjo denominado Projeto Orla. Até o momento, muito pouco desse projeto foi concretizado: na orla de Palmas, conhecida como a Praia da Graciosa, existem apenas dois restaurantes, que, a bem da verdade, são pouco frequentados pela população local.

Grande parte dos comerciantes que atuavam na antiga praia da Graciosa, na margem oposta do rio, ainda não recebeu a esperada indenização, E como, na nova praia, o número de restaurantes e bares é pequeno, poucos dos antigos comerciantes se mantiveram à frente de seus negócios, e em alguns casos não são os mesmos que exploravam atividades comerciais na antiga praia.

Dentre os grupos de pessoas impactadas que viviam na região do entorno de Palmas, destacam-se aqueles que extraíam areia, seixo e brita para a construção civil. Todos eles foram retirados do local num curto espaço de tempo, e muitos deles não foram indenizados, nem realocados em lugares onde pudessem exercer as atividades que Ihes garantia a sobrevivência. ${ }^{21}$

Assim, a construção da usina Luís Eduardo Magalhães causou impactos não apenas físicos nas cidades envolvidas, mas também na vida de toda a população ribeirinha. Inúmeras famílias - formadas, em sua grande maioria, por pequenos produtores rurais - foram desapropriadas de suas terras ou mesmo deslocadas para reassentamentos onde não havia estrutura agricultável; outras migraram para as cidades, ingressaram em novas

20 Jornal do Tocantins, Palmas, 3/12/2001.

21 JUSTINO, Marcelo Lopes. (In)sustentabilidade socioeconômica dos reassentamentos Mariana e olericultores, Porto Nacional - TO. Palmas: Universidade Federal de Tocantins, 2012 (Desenvolvimento Regional, Dissertação de mestrado). 
atividades e, com isso, suas referências adquiridas durante várias gerações foram submersas pelo lago.

Com a construção da usina e a formação do reservatório, o patrimônio histórico das cidades históricas foi afetado. É o caso de Porto Nacional, ${ }^{22}$ que, em nome do progresso, perdeu monumentos que representavam a história secular da cidade, principalmente no contexto arquitetônico. Parte das fachadas de seus casarios coloniais, situados em frente à Matriz de Nossa Senhora das Mercês, foi derrubada para dar lugar à Avenida Beira Rio, que iria representar "a modernidade e o desenvolvimento do lugar".

\section{Gênero e memórias de mulheres reassentadas}

Em estudo sobre o patrimônio histórico de Porto Nacional, Messias mostra não só a perda do patrimônio material, mas também os impactos dessas perdas para as pessoas que tinham o rio como o seu referencial de trabalho, de lazer e de prazer. Através de narrativas de várias pessoas, muita delas mulheres, a autora estabelece a relação delas com o rio, relatando as perdas sofridas com a formação do lago, principalmente no que se refere às lembranças do lazer e aos sentimentos provocados pela falta do rio. É o que reflete a fala de Dona Célia:

Aquela água verdinha, linda. Quando o céu estava azul, ele parecia ser azul, mas ela era mais verde por causa da mata que tinha às margens. E assim o rio para mim era tudo e agora acabou. Não é mais aquele rio. Ele está inchado, sofrendo, amargurado, pedindo socorro e isso faz com que a gente sofra também. Eu sinto dores no coração em ver o rio Tocantins, assim desse jeito. ${ }^{23}$

Sentimento igual pode ser detectado no poema "Barragem", de autoria de Pedro Tierra, antigo morador de Porto Nacional:

O rio teima em manter-se rio, corrente:

uma veia de esmeralda líquida e retesa

varando o ventre do lago,

feito alma submersa

e luminosa a the dar sentido.

Vencido, o rio se abranda em barros e silêncios.

Grávido, cálido, fermentado.

Engendrando o desconhecido. ${ }^{24}$

22 Porto Nacional, uma das cidades mais antigas do Estado do Tocantins, está localizada à margem direita do Rio Tocantins e dista sessenta quilômetros de Palmas, capital do Estado. Surgiu no período da mineração, no século XVIII, não com a extração do ouro, mas como entroncamento para a chegada de produtos que vinham do norte do país e eram transportados de barco pelo Rio Tocantins, para abastecer as zonas mineiras. Pela sua localização privilegiada - era um dos poucos arraiais dotado de um porto fluvial -, logo tornou-se conhecida em toda a região. PARENTE, Temis Gomes. Lembranças de outrora, p.71.

23 MESSIAS, Noeci Carvalho. Patrimônio cultural, p.71.

24 TIERRA, Pedro. O porto submerso. Brasília: Editora Independente, 2005, p.85. 
Para as pessoas que viveram em suas margens, o rio está desfeito em seu leito, "inchado", "vencido" e sofrido por estar represado.

Falar do Rio Tocantins com a comunidade local é evocar todo um torrencial de lembranças e de bons momentos. Ao relembrar como era o rio, o ribeirinho parece voltar àqueles tempos de outrora, quando os lugares Ihes pareciam maravilhosos. A situação atual representa uma espécie de corte nos lugares de um passado não muito distante. A falta do Rio Tocantins constitui uma perda cultural em todos os aspectos, na inspiração dos poetas, dos músicos e da população como um todo. Essa perda, porém, só é percebida quando essas pessoas têm a oportunidade de falar. Desse modo, através do registro dessas falas para trabalhos como este, é possível perceber o quanto as pessoas se lembram de fatos que nem elas próprias se lembravam de ter vivido. Essas lembranças são vivências de um tempo passado, que de uma hora para outra pareciam ter sido perdidas.

Afinal, só nas narrativas de quem viveu aquele momento será possível detectar os sentimentos de perdas que perpassam as memórias dos antigos moradores ribeirinhos do Rio Tocantins. Assim, através do estímulo às memórias dos antigos moradores que foram arrancados dos seus espaços e moradias, pode-se entender o que diz Pierre Nora. ${ }^{25}$ Para esse historiador, não existe memória espontânea, assim sendo a necessidade dos homens de alimentarem a história, com os resquícios do passado, bem como de construírem e manterem os referidos lugares da memória, traduz a busca, pelo ser humano, da eternidade e da identidade social.

Em estudos realizados no povoado de Pinheirópolis, município de Porto Nacional, a dor daquela população, por ter de abandonar suas casas, de se afastar de seus antigos vizinhos, de abandonar suas lembranças e costumes adquiridos durante várias gerações, foi facilmente percebida. Os impactos sofridos, mormente pelas mulheres, foram irreversíveis, principalmente no contexto cultural: ${ }^{26}$ elas haviam perdido o seu "território", não só no que se refere aos espaços de suas casas, de seus quintais, mas também de suas memórias.

É interessante perceber que, quando falam sobre as festas tradicionais, as mulheres mostram claramente uma preocupação em manter suas raízes e tradições. Para elas, as festas religiosas, com as mudanças, também sofreram modificações culturais, principalmente na estrutura física, porque algumas tradições, como as das barracas que eram erguidas todos os anos na época de festejos, na antiga Pinheirópolis, foram inviabilizadas. É o que narra Dona Nonita:

25 NORA, Pierre. Entre memória e história: a problemática dos lugares. Projeto História, São Paulo, v.10, 1993.

26 O termo "cultura" é aqui entendido não como curiosidade ou exotismo, mas algo enraizado na realidade social, impregnado de um sentido intenso, por meio do qual as pessoas se expressam, reagem, exercendo, ou não, suas possibilidades criativas, formando os processos de mudança social KHOURY, Yara Aun. Narrativas orais na investigação da História Social. Projeto História, São Paulo, n.22, p.80, 2001. 
As festas continuam, mas tem uma diferença lá todo ano, desde que eu conheço era feito um barracão de palha. Depois que mudou pra cá isso nunca aconteceu, faz a festa aqui no centro comunitário, então eu acho que isso perdeu um pouco de nosso costume. (Entrevista do dia 13/01/2004).

Quando indagadas como eram as festas do padroeiro no antigo povoado, as mulheres, em um primeiro momento, respondem não ter havido mudanças profundas, uma vez que se mantêm as coroações do imperador e dos capitães de mastros, a folia, a dança da súcia, as novenas e as missas. No entanto, quando se mencionam as barracas de palha, elas identificam as mudanças: as muitas árvores que davam sombra já não existem mais, os rituais antes e durante os festejos. Para essas mulheres, a preparação da festa sempre envolvia os vizinhos, tanto os de perto como os mais distantes, e isso formava uma rede de solidariedade que só era perceptível durante as festas. Fica claro, nas narrativas dessas mulheres, que as referências às barracas de palhas e às arvores são uma espécie de extensão das suas casas, dos encontros ocorridos antes e durante os festejos, pois "os espaços realmente habitados trazem a essência da noção da casa". ${ }^{27}$ Durante as entrevistas, tornou-se fácil constatar que, muitas vezes, nem mesmo as mulheres são capazes de enumerar as mudanças que se sucederam, provavelmente por não identificarem as relações dos espaços anteriormente vividos com as lembranças do que vivenciaram. Desse modo, falar das barracas e das árvores, para essas mulheres, é uma maneira de fazê-las lembrar dos encontros e das pessoas que circulavam por aqueles antigos espaços.

As entrevistadas ${ }^{28}$ ainda dizem que a mudança afetou os laços de amizade e o companheirismo entre os vizinhos. A conversa à porta das casas, a reunião para tomar um café e contar as novidades já não acontecem mais, fazendo com que os vizinhos sejam hoje apenas meros conhecidos e nada mais.

O que se percebeu é que essas mulheres - não só elas, mas grande parte da população que morava às margens do rio - perderam muito com a transferência para outros locais de moradia. Ficaram para trás partes de suas identidades, mesmo que tentem manter as antigas tradições. Elas sabem, porém, que, com o passar do tempo, as antigas práticas vão sendo abandonadas. Estão cientes de que os adolescentes de hoje, por não conhecerem as festas e a cultura dos antigos povoados ou por terem-nas conhecido somente na infância, não conseguem atribuir importância à história de seu povoado.

27 BACHELARD, Gaston. A poética do espaço. São Paulo: Martins Fontes, 1993, p.25.

28 Todas as entrevistas estão digitalizadas e catalogadas no Núcleo de Estudos das Diferenças de Gênero - UFT Campus de Porto Nacional. Todas essas pesquisas foram financiadas pelo CNPQ, em forma de projetos e através de Bolsa de Produtividade. 
Assim, os costumes e as referências antigas no modo de viver foram abandonados de um dia para outro, com modificações substanciais em suas vidas, devido à formação do reservatório. Ao mesmo tempo, essas mulheres presenciaram não só as transformações da natureza, mas também - e de modo efetivo - vivenciaram as alterações das relações do grupo com outros grupos e dos grupos com o lugar. As lembranças das mulheres têm sido permeadas pela saudade de um espaço que já não existe mais, ganham contornos de gênero, não somente por serem lembradas por mulheres, mas principalmente por se reportarem a lugares e tempos que, costumeiramente, são definidos, nas relações, como próprios de mulheres.

Na memória das mulheres a saudade é sempre presente. Esta, porém, não se refere somente a um tempo que não volta mais, refere-se, também, a um espaço que já não existe e que foi seu "território" de referência, responsável pela constituição de subjetividades. A fala das mulheres não é rimada, nem elaborada como na poesia citada acima, mas suas memórias trazem os mesmos sentimentos que a inspiram: saudades, referência a um tempo mais feliz, lembranças de árvores, plantas, casas, enfim, de relações.

Para essas mulheres, foram deixadas para traz, suas terras suas plantações, suas formas tradicionais de viver, sem contar com suas lembranças, seus sentimentos de perda muitas vezes adormecidas até que começam a falar, como foi o caso com muitas das entrevistadas. Nas falas das muIheres, percebe-se o custo social a que se viram obrigadas a arcar com a construção da usina: dor, sacrifício, e perdas.

Através das falas dessas mulheres percebemos como eram seus cotidianos, suas relações vivenciadas naturalmente. Durante as entrevistas elas buscam na memória saber como eram suas vidas antes da formação do reservatório e como suas rotinas de vida mudaram, elas recordam e organizam essas lembranças, principalmente, no que se refere às suas atividades rotineiras de labutar nas roças, nos quintais e no cotidiano doméstico.

Ao analisar essas falas, ficam evidentes as delimitações de diferentes papéis entre os membros familiares e, particularmente, as representações formadoras do lugar ocupado por essas mulheres nas suas narrativas: percebe-se a construção e reprodução desses papéis vividos e ou representado por elas.

É através dessas memórias que as mulheres entrevistadas deixam transparecer os papéis de gênero em que elas viviam e o que se esperava que elas desempenhassem. Bourdieu nos lembra como a divisão das atividades atribuídas aos sexos está implicada numa subordinação de gênero. ${ }^{29}$

Podemos, portanto, pensar os papéis de gênero representado pelas mulheres dos reassentamentos pesquisados, como comportamentos e

29 BOURDIEU, Pierre. A dominação masculina. Rio de Janeiro: Bertrand do Brasil, 1999, p.18. 
atitudes socialmente esperados dos membros de uma sociedade, diferenciados por sexo, pois falar de papéis de gênero é falar de padrões, regras, que uma dada sociedade estabelece para com seus membros. Eles definem comportamentos e formas das pessoas se relacionarem. $\mathrm{O}$ aprendizado de papéis leva ao conhecimento e a internalização de modelos daquilo que se considera adequado, ou não, para um homem ou para uma mulher em dada sociedade. ${ }^{30}$

Por fim, cabe ressaltar que as desvantagens causadas pelos reservatórios artificiais, nas construções de usinas hidrelétricas, assumem a feição de impactos ao meio ambiente e às formas de viver da população ribeirinha, tanto nos aspectos econômicos do território afetado quanto nos culturais. E esses impactos resultam em desagregação do sistema econômico de subsistência de muitas famílias que tradicionalmente viviam as suas relações sociais em um determinado espaço e em um determinado grupo.

A titulo de conclusão: segundo análises da Comissão Mundial de Barragens, na maioria das vezes, os projetos de barragem ampliam as disparidades de gênero, seja pela imposição desproporcional dos custos sociais sobre as mulheres, seja pela alocação desigual dos benefícios por eles gerados. Embora não se possa atribuir a esses projetos a responsabilidade pela desigualdade nas relações de gênero, projetos nos quais essa questão não é levada em consideração podem, na melhor das hipóteses, não alterar as condições preexistentes e, na pior, agravá-las ainda mais. ${ }^{31}$

É isso que ocorreu e vem ocorrendo no Estado do Tocantins. O desenvolvimento propagado com as construções de grandes empreendimentos não atinge a maioria das pessoas do local e, no caso das hidrelétricas, particularmente as mulheres por estarem excluídas do processo de planejamento; excluídas das ações mitigadoras dos problemas advindos, por exemplo a questão do abastecimento domestico da agua, atividade diretamente ligada às questões domésticas e portanto de mulheres, ocasionando e fortalecendo as disparidades de gênero.

30 PARENTE, Temis Gomes. Gênero e memória de mulheres desterritorializadas. ArtCultura, Uberlândia, v.9, p.104, 2007.

31 WORLD COMMISSION ON DAMS. Dams and development: a new framework for decision-making. London: Earthscan, 2000, p.114-115. 